\title{
O PARQUE LINEAR DO CÓRREGO DO ÓLEO EM UBERLÂNDIA- MG: AVALIAÇÃO DAS CONDIÇÕES DE CONSERVAÇÃO E PERCEPÇÃO DA POPULAÇÃO LOCAL
}

\author{
Lorraine Campos Martins
}

(Universidade Federal de Uberlândia, Geógrafa, Mestre em Meio Ambiente e Qualidade Ambiental, lorrainecampos.geo@gmail.com)

Resumo: Os parques lineares surgiram como uma iniciativa que possibilitaria a conservação das áreas de preservação permanente urbanas, contribuindo para o equilíbrio ambiental nas cidades, modificando a interação entre a população e os cursos d'água e integrando a os rios e suas margens ao tecido urbano. No Brasil, há uma legislação específica que orienta a gestão de áreas de preservação permanente, sobretudo em áreas rurais. Porém, o cuidado com as APPs urbanas fica a cargo da administração municipal, cabendo a ela a gestão destas áreas. A implantação de parques lineares contribui para melhoria da a qualidade ambiental e qualidade de vida da população das cidades. Mas, além disto, cabe salientar a importância do monitoramento de suas condições estruturais e ambientais, a fim de assegurar que sejam alcançados os objetivos para os quais os parques foram criados. Ademais, a participação da população é imprescindível para a orientação de intervenções que porventura se façam necessárias. Desta maneira, este estudo traz uma avaliação das condições de conservação ambiental e estrutural do Parque Linear do Córrego do Óleo, em Uberlândia-MG, e percepção da população residente nos bairros próximos, objetivando orientar possíveis medidas a serem tomadas, desde intervenções estruturais a ações de educação ambiental.

Palavras- chave:APPs urbanas, fundos de vale, planejamento urbano.

THE LINEAR PARK OF THE ÓLEO STREAM IN UBERLÂNDIA-BRAZIL: EVALUATION OF THE CONDITIONS OF CONSERVATION AND PERCEPTION OF THE LOCAL POPULATION

Artigo recebido para publicação em 11 de Abril de 2017 


\section{GEOAMBIENTE ON-LINE}

Revista Eletrônica do Curso de Geografia - UFG/REJ

Graduação e Pós-Graduação em Geografia

http://revistas.ufg.br/index.php/geoambiente/index

Apoio: PRPG/PROAPUPEC

Jataí-GO | n 29 | Jul-Dez/2017

Abstract: The linear parks emerged as an initiative that would allow the conservation of permanent urban preservation areas, contributing to the environmental balance in the cities, modifying the interaction between the population and the water courses and integrating the rivers and their banks into the urban layout. In Brazil, there are specific laws that guide the management of permanent preservation areas, especially in rural areas. However, the management of the urban APPs is the municipal administration incumbency, as it is the body responsible for the planning of these areas. The implementation of linear parks contributes to the improvement of the environmental quality and the quality of life of the cities' population. Furthermore, it is substantial to enhance the importance of monitoring their structural and environmental conditions in order to ensure that the objectives for which the parks are created are achieved. In addition, the participation of the population is essential for the orientation of interventions that may be necessary. Therefore, this study provides an assessment of the environmental and structural conservation conditions of the Óleo stream Linear Park, in Uberlândia-Brazil, and the perception of the population living in the nearby neighborhoods, aiming to guide possible measures to be taken, from structural intervention to environmental education actions.

Keywords: UrbanAPPs, valley bottom, urban planning

\section{PARQUE LINEAL DEL ARROYO DELÓLEO EN UBERLANDIA-MG: EVALUACIÓN DE LAS CONDICIONES Y PERCEPCIÓN DE LA POBLACIÓN LOCAL}

Resumen: Los parques lineales han surgido como una iniciativa que permita a la conservación de las áreas urbanas de preservación permanente, contribuyendo al equilibrio del medio ambiente en las ciudades mediante la modificación de la interacción entre la población y los cursos de agua y la integración del río y sus riberas en el tejido urbano. En Brasil, hay una ley específica que guía la gestión de las áreas de preservación permanente, sobre todo en las zonas rurales. Sin embargo, la atención a las APP urbanas es responsabilidad de la administración municipal, dejándola el manejo de estas áreas. La implantación de parques lineales contribuir a mejorar la calidad ambiental y la calidad de vida de la población de las ciudades. Pero más allá de esto, hay que señalar la importancia de supervisar sus condiciones estructurales y ambientales con el fin de garantizar el logro de los objetivos para los que fueron creados los parques. Por otra parte, la proporción de la población es esencial para la orientación de las intervenciones que puedan resultar necesarias. 


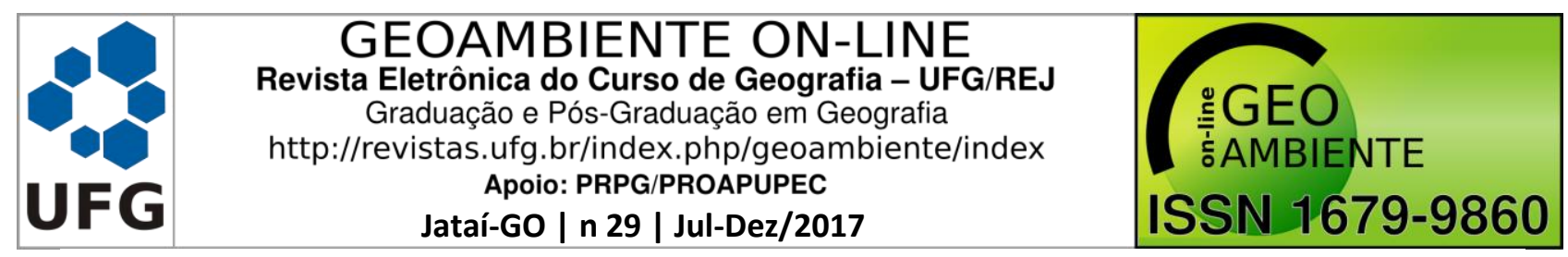

Por lo tanto, este estudio proporciona una evaluación de las condiciones ambientales y la conservación estructural de Parque Lineal del Arroyo delÓleo en Uberlândia, Minas Gerais, y la percepción de la población que vive en lugares cerrados, con el objetivo de orientar a los posibles pasos a seguir, a partir de medidas estructurales para acciones educación ambiental. Palavras clave: APP urbanas, fondo de los vales, planeamiento urbano

\section{INTRODUÇÃO}

Os rios possibilitaram a formação das primeiras civilizações urbanas. Boa parte das primeiras cidades do mundo se formou próximo aos rios, a partir de aldeias agrícolas,a fim de garantir o abastecimento da população e favorecer as comunicações e o comércio. Desde então, a relação entre os rios e a cidade passou por severas mudanças. (BAPTISTA;CARDOSO, 2013)

A integração de cursos d'água e suas margens ao tecido urbano em cidades europeias como Paris, Londres e Berlim no século XVII, surgiu como uma tentativa de amenizar os efeitos da urbanização rápida, consequência do desenvolvimento da industrialização. Embora os primeiros registros de projetos com tal objetivo tivesse a priori cunho predominantemente paisagístico e viário, eles serviram para inspirar ou ter seus objetivos incorporados a ações futuras em cidades de todo o mundo, adquirindo caráter ambiental à medida que a questão ganhava importância no cenário mundial.

Para Rolnik (2012), a história de cada cidade se materializa no seu espaço. Assim, as formas de ocupação ao longo do tempo, deixam suas marcas no espaço como uma expressão das relações homem-natureza e da sociedade entre si. Isso pode ser observado também quando se trata das relações entre a sociedade e o ambiente por ela construído e projetado, e os elementos naturais, como os cursos d'água.

O levantamento dos indícios deixados por elementos naturais subjugados na paisagem urbana consolidada, como córregos e rios, cria elos que possibilitam a compreensão de aspectos passados. É revelada, desta forma, a persistência de alguns elementos primitivos que ainda se fazem presentes, mesmo com todas as transformações ocorridas no espaço urbano. (CABRAL, 2012).

Nesse sentido, a importância de áreas de preservação, como as APPs e os parques, naestrutura urbana vai além das possibilidades de uso destes espaços pela população, 


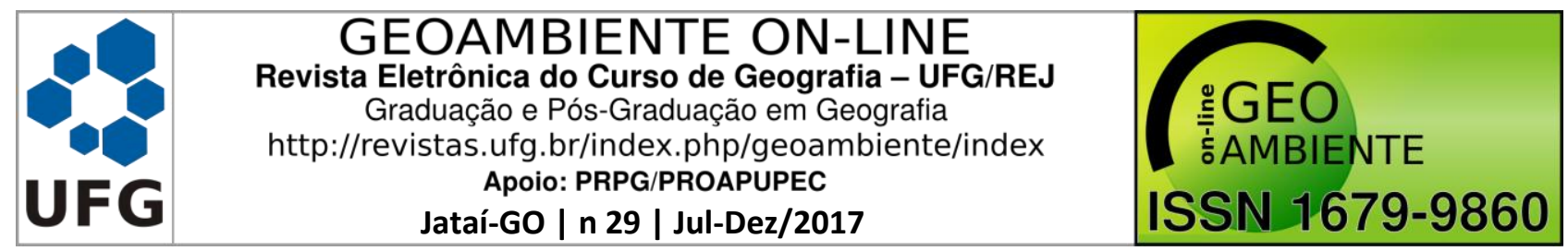

masinclui apromoção do equilíbrio ecológico no espaço urbano, além da contribuição com a beleza cênica da cidade, garantindo a biodiversidade local (BEZERRA et al, 2016).

As cidades são ambientes descaracterizados do natural. Assim, os elementos naturais presentes na paisagem urbana, como as áreas verdes, são definidos de maneira muito ampla, por considerar todo e qualquer componente vegetal. (GRISE et al, 2016).

Basicamente, as áreas verdes são conceituadas por Maciel e Barbosa (2015) como locais de vegetação natural (arbórea ou não) presentes no ambiente urbano como praças, parques, terrenos baldios, hortas, geralmente com o objetivo ornamentar a cidade, proporcionar lazer e melhorar a qualidade de vida da população urbana.

Os parques lineares surgiram inicialmente como um conceito que englobava a funcionalidade viária, a beleza estética, navegabilidade e proteção ecológica, como nos Planos de Lenné para Berlim, por exemplo, criados entre 1840 e 1850.Posteriormente, com a criação dos Parkways nos Estados Unidos, os parques lineares foram planejados como forma de integração linear entre espaços abertos, otimizando o tráfego e dotando a cidade de beleza cênica. (FRIEDRICH, 2007).

A evolução dos parques engloba posteriormente diferentes funcionalidades, englobando a preservação ecológica e a ligação de áreas verdes com o uso humano, principalmente em práticas de lazer. (GALENDER, 2005)

Especialmente no Brasil, durante o período chamado sanitarista, os córregos urbanos foram vistos como vetores de doenças que assolavam a população e tornavam a cidade um ambiente feio e sujo, por conta do constante lançamento de esgoto em suas águas. As medidas corretivas implantadas nesta época se resumem na artificializarão dos sistemas fluviais e modificação de sua dinâmica, principalmente a canalização. (COTA et al, 2016)

Apesar de ser a solução mais prática na época, visto que em boa parte das ocorrências eram construídas as chamadas avenidas sanitárias sobre estes córregos, a fim de otimizar o tráfego urbano, este tipo de tratamento contribuiu para alimentar o distanciamento entre o córrego e o território urbano e à própria população. (MACEDO, 2009)

Além disso, a canalização e outras interferências estruturais bruscas nas margens e nos próprios cursos d'água causam prejuízos severos à cidade, como o agravamento de inundações naturais, inundações pontuais devido ao estrangulamento da seção do rio causado 
por intervenções estruturais, erosão, assoreamento, remanso, entre outros problemas, como destacou Tucci (2007), além de comprometer severamente a dinâmica da fauna e da flora e o clima no ambiente urbano.

A gestão ineficiente dos fundos de vale urbanos pode contribuir também para o agravamento de problemas sociais, como o assenta mento humano em áreas consideradas impróprias, o que além de causar danos materiais contribui severamente para a veiculação de doenças. A manutenção da mata ciliar pode ajudar a minimizar o grau de poluição de um curso d'água, como afirma Macedo (2009). No entanto, é necessário atentar-se às fontes geradoras de poluição para garantir de maneira mais eficaz a manutenção da qualidade da água.

As legislações urbanística e ambiental a nível nacional tratam as áreas de proteção permanente urbanas de maneira muito clara. Tanto o antigo quanto o novo código florestal focam sua discussão nas APPs em área rural. Já as leis urbanísticas principais, representadas sobretudo pelo Estatuto da Cidade, tratam prioritariamente questões de moradia, abordando o meio ambiente urbano de uma forma muito superficial. Fica a cargo, portanto, da legislação municipal a gestão das áreas de fundo de vale urbanas. (SEPE et al, 2014)

Nas últimas décadas, principalmente em grandes cidades, foram desenvolvidos programas que visam a recuperação, revitalização ou proteção de córregos urbanos. Tais programas são de fundamental importância para a preservação dos recursos hídricos na área urbana, para a garantia de um ambiente urbano equilibrado e para estreitar as relações entre a população e o ambiente natural nas cidades.

É importante destacar, no entanto, a importância do monitoramento dos resultados de tais programas, como apontou Lara (2014) em sua análise crítica dos programas de recuperação de córregos urbanos PDA e PRRU no Córrego Belém, em Curitiba.

Além disso, vale ressaltar que quanto maior for o nível de degradação do córrego em questão, mais dispendiosas serão as ações necessárias à sua recuperação, e menores as chances de alcançar resultados mais eficazes, como observaram Cota et al (2016) ao analisar o programa DRENURBS, proposto pela prefeitura de Belo Horizonte. Ao tratar destes programas, os autores destacam a importância do monitoramento dos resultados das intervenções propostas, a fim de verificar a eficácia das mesmas. 


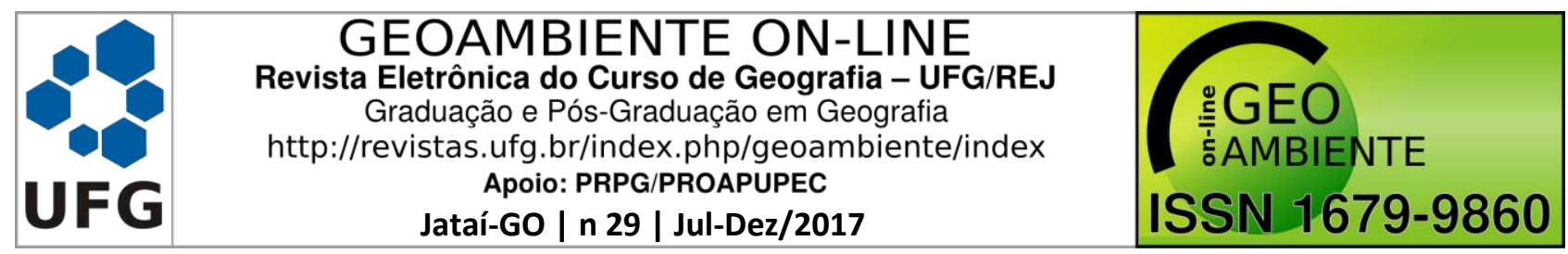

Considerando a importância ambiental e social dos parques lineares e a necessidade do monitoramento destas áreas e aprimoramento das ações nelas desenvolvidas, este trabalho pretende avaliar a condição atual do Parque Linear do Córrego do Óleo, localizado no setor Oeste da cidade de Uberlândia - MG, no que diz respeito às suas características ambientais, estado atual de conservação e a relação da população dos bairros abrangentes com o parque linear e sua visão a respeito do córrego e do próprio parque.

\section{Área de estudo}

A Bacia do Córrego do Óleo está localizada no setor oeste da cidade de Uberlândia, e abriga diversos bairros da cidade como Luizote de Freitas, Mansour, Chácaras Tubalina, Cidade Verde, Jardim Europa, Chácaras Tubalina, Planalto e São Lucas.

A bacia hidrográfica do Córrego do Óleo ocupa uma área que corresponde a aproximadamente $10 \%$ do perímetro urbano da cidade. Esta abrangência faz com que haja uma dinâmica direta com a população do seu entorno, o que resulta em vários tipos de impactos no córrego e em suas margens. A composição geológica desta bacia consiste basicamente em basaltos do grupo Serra Geral, à jusante, e o Arenito Marília, à montante, o que faz com que o córrego seja mais entalhado à medida que corre para sua foz. (FARIAS et al, 2009)

Entre as áreas de APP definidas como parques pela prefeitura de Uberlândia para esta bacia estão o Parque Municipal Natural do Óleo, localizado na área da nascente do córrego, no Bairro São Lucas, o Parque Mansour e o Parque Municipal Luizote de Freitas, e o Parque Linear do Córrego do Óleo, cuja localização está representada na Figura 1.

Apesar de se estender por bairros populosos como o Luizote de Freitas, o Parque Linear do Córrego do Óleo não abrange toda a área de APP do córrego. Além disso, não existe uma conexão entre este e os demais parque existentes na mesma bacia, nem mesmo com outros parques lineares como o do Rio Uberabinha, do qual o córrego do Óleo é afluente. A prefeitura de Uberlândia publicou em 2011 um estudo para a conexão destas áreas, denominado Parque Municipal Natural das Graças. No entanto, a proposta ainda não se concretizou. 


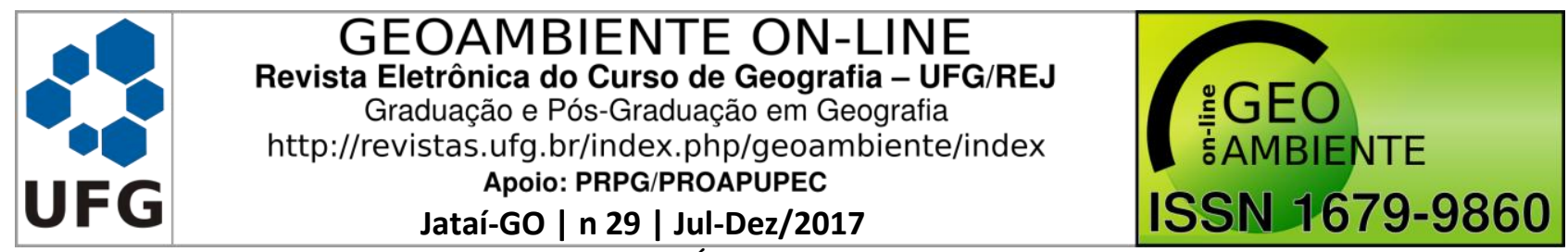

O Parque Linear do Córrego do Óleo foi criado mais recentemente, sendo inaugurado em setembro de 2014, com alguns equipamentos de lazer como pista de caminhada, quadra de esportes com arquibancada, quiosques, bancos e mesas de concreto e ciclovia.

Figura 1: Mapa de localização do Parque Linear do Córrego do Óleo, em Uberlândia - MG

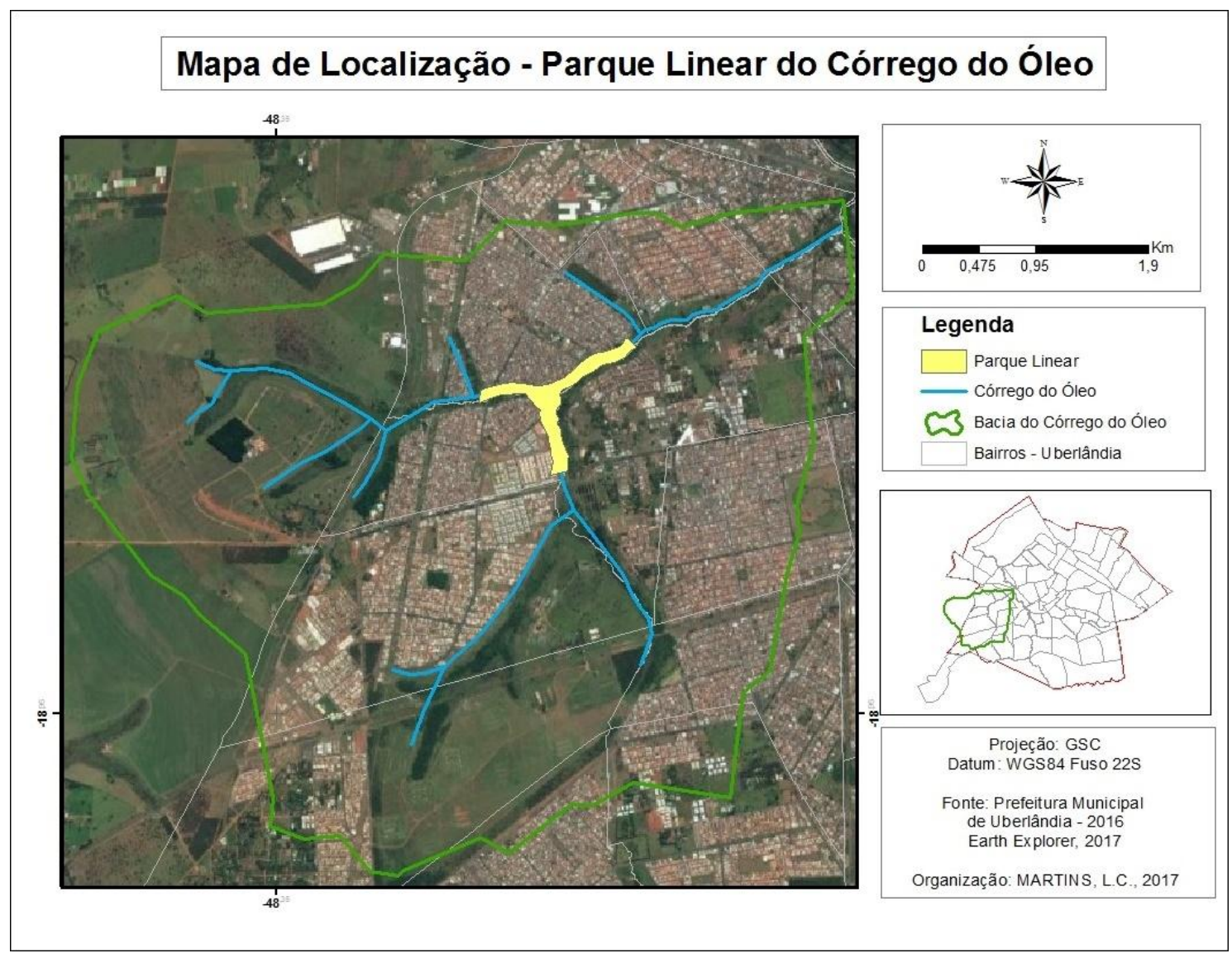

De acordo com o zoneamento do uso do solo urbano definido pela lei complementar 525 de 2011, regiões dos fundos de vale, praças, parques, bosques e outras áreas similares de interesse público, são definidas como zonas de preservação e lazer, cuja proteção é obrigatória. Nesse tipo de zona, a ocupação e edificação somente são permitidas quando utilizadas para recreação, mediante projetos aprovados por órgãos responsáveis pelo planejamento urbano e pela preservação do meio ambiente. (UBERLÂNDIA, 2011)

Entre as diretrizes ambientais propostas no Plano Diretor da cidade (Lei Complementar $\mathrm{N}^{\circ}$ 432/2006), estão a recuperar os fundos de vales, nascentes e córregos das áreasurbana e rural, implantar ou adequar sistemas de dissipação noslançamentos das águas pluviais, para possibilitar a recuperação das áreasde preservação e criação de parques lineares 


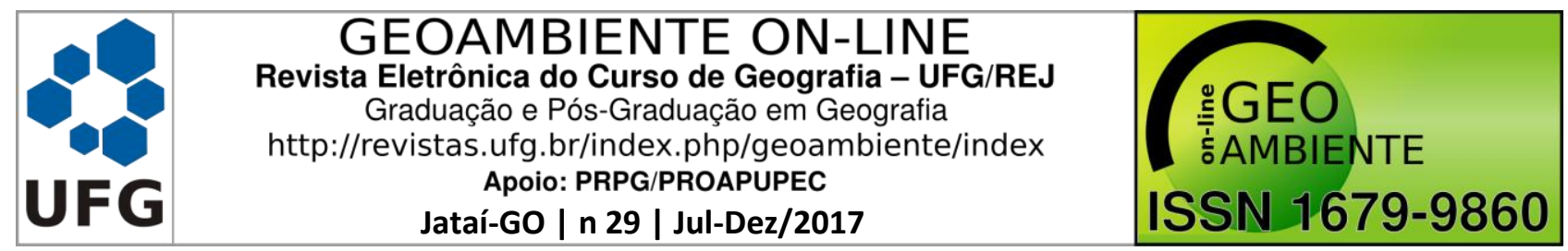

e unidades de conservação e a garantia de proteção dos recursos hídricos e vegetais, aredução dos problemas de drenagem e a criação de áreas para lazer naconcepção dos parques, áreas de preservação e unidades de conservação.

Antes da criação do Parque Linear do Córrego do Óleo, alguns anos depois da divulgação do plano diretor, alguns estudos avaliaram as condições de preservação de diversas áreas da bacia, e encontraram diversos problemas. Farias et al (2009) relataram em seu estudo a ocupação irregular das margens do córrego nas áreas próximas à nascente, como a criação de gado para a produção de leite.

Magalhães e Silva (2011) observaram grande quantidade de resíduos sólidos espalhados e o desmatamento da mata de galeria, o que pode contribuir para o desenvolvimento de processos erosivos. Pereira e Ribeiro (2012), a partir de análise de amostras de água do Córrego do Óleo, concluíram que parâmetros de cádmio, chumbo e cromo apresentaram concentrações muito elevadas.

A criação do Parque Linear do Córrego do Óleo, apesar de viabilizar a interação da população dos bairros com o córrego, não foi capaz de garantir que não ocorressem problemas semelhantes aos observados nos estudos acima citados. Desta forma, a metodologia deste artigo consiste em uma análise da atual situação de conservação do parque linear do córrego do óleo e à consulta da população dos bairrospróximos quanto ao próprio parque e a este estado atual, buscando compreender de que forma ela interage com o córrego e até que ponto esta interação pode influenciar na utilização e na conservação do parque.

\section{METODOLOGIA}

\section{Análise das condições de conservação do Parque Linear do Córrego do Óleo}

Esta etapa do trabalho foi feita a partir da realização de trabalhos de campo em toda a área do Parque Linear. Entre as observações realizadas durante o trabalho estão a análise de condições da vegetação, ocupações irregulares e ações pontuais de conservação ambiental, presença de resíduos sólidos nas margens e no leito do córrego, degradação dos equipamentos de lazer instalados no córrego e finalização da implantação de outros equipamentos. 


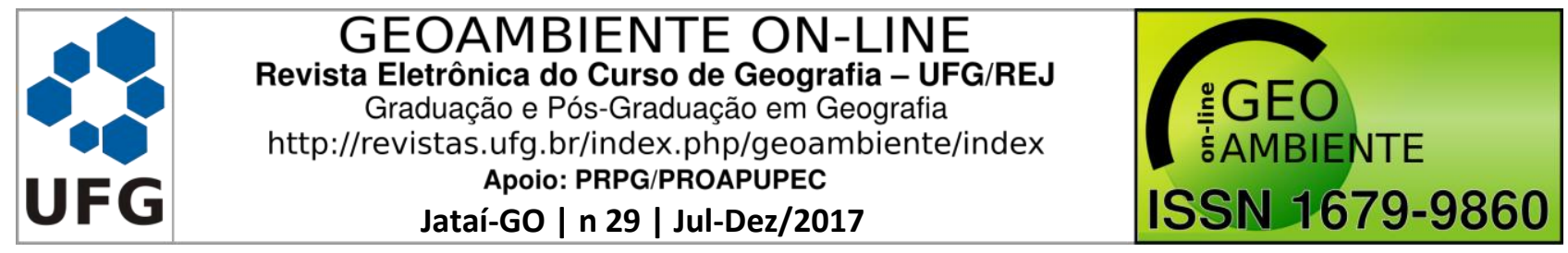

A análise das condições de conservação ambiental, entre outros tipos de análise como condições de drenagem, qualidade da água, processos erosivos, entre outras, é de fundamental importância para monitorar a área e apontar os problemas encontrados às autoridades responsáveis por ela, verificar a efetividade das medidas adotadas.

\section{Pesquisa com a população}

A segunda etapa desta pesquisa consiste na aplicação de um questionário com moradores dos bairrosLuizote, Mansour, Jardim Europa, entre outros, localizados nas proximidades do córrego. O principal objetivo do questionário é descobrir como a população desses bairros percebe e interage com esta área, quais as mudanças ou melhorias desejadas pela população e as motivações da população para frequentar ou não frequentar o parque.

De acordo com Cunha e Cannan (2015) a percepção ambiental vem sendo tratada desde 1973 pela UNESCO como um instrumento de planejamento ambiental, em conjunto com a a educação e a gestão ambiental, devendo se destacar como forma de defesa do meio ambiente natural, de conscientização reivindicação das pretensões sociais.

É de extrema importância que a população seja consultada e participe da construção do planejamento das cidades, sobretudo das áreas de fundo de vale (Friedrich, 2007), pois além de o conceito de qualidade ambiental urbana ser bastante subjetivo, a visão da população a respeito dos córregos e áreas verdes urbanas é influenciada pelas intervenções realizadas na cidade e podem, em contrapartida, influenciar positiva ou negativamente nas medidas adotadas nesta e em outras áreas.

Para tanto, foi elaborado um questionário conciso, com dez perguntas, sendo três questões fechadas e sete questões abertas. A presença de tantas questões abertas se justifica por se tratar de uma questão subjetiva e pela tentativa de evitar respostas engessadas, o que não inviabilizou a análise de resultados.

Foram aplicados 30 questionários, por considerar que, se esta quantidade for aplicada de maneira distribuída, seria suficiente para esta análise.As entrevistas foram realizadas de maneira aleatória com moradores dos bairros de abrangência do Parque Linear e pessoas que frequentam ou trabalham nas proximidades. 


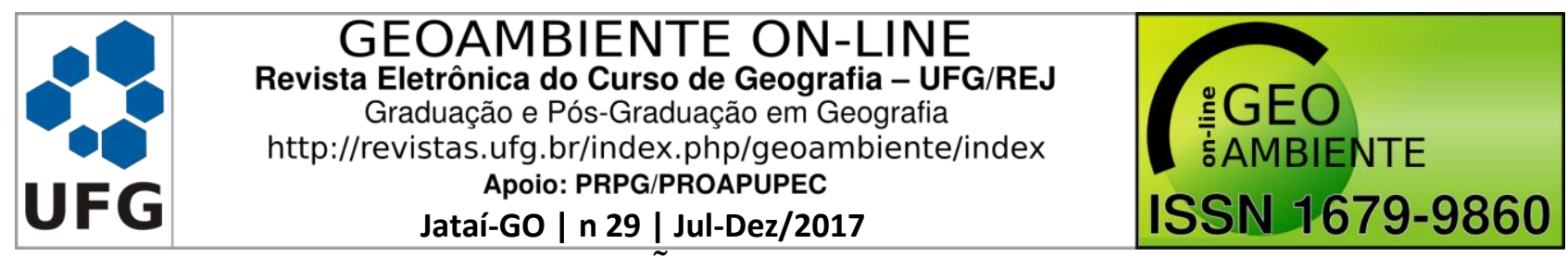

\section{RESULTADOS E DISCUSSÃO}

\section{Condições de conservação}

Entre os equipamentos instalados no Parque Linear do Córrego do Óleo, o primeiro foi a pista de caminhada. Esta pista é utilizada pela população para caminhadas, corridas, e por vezes é utilizada também como ciclovia. Apesar dos projetos, não há uma ciclovia separada da pista de caminhada. Atualmente, a pista apresenta problemas de estrutura (Figura 2) e sua iluminação é precária, impossibilitando seu uso noturno e facilitando o aumento da criminalidade no parque.

Figura 2: Danos na estrutura da pista de caminhada do Parque Linear do Córrego do Óleo

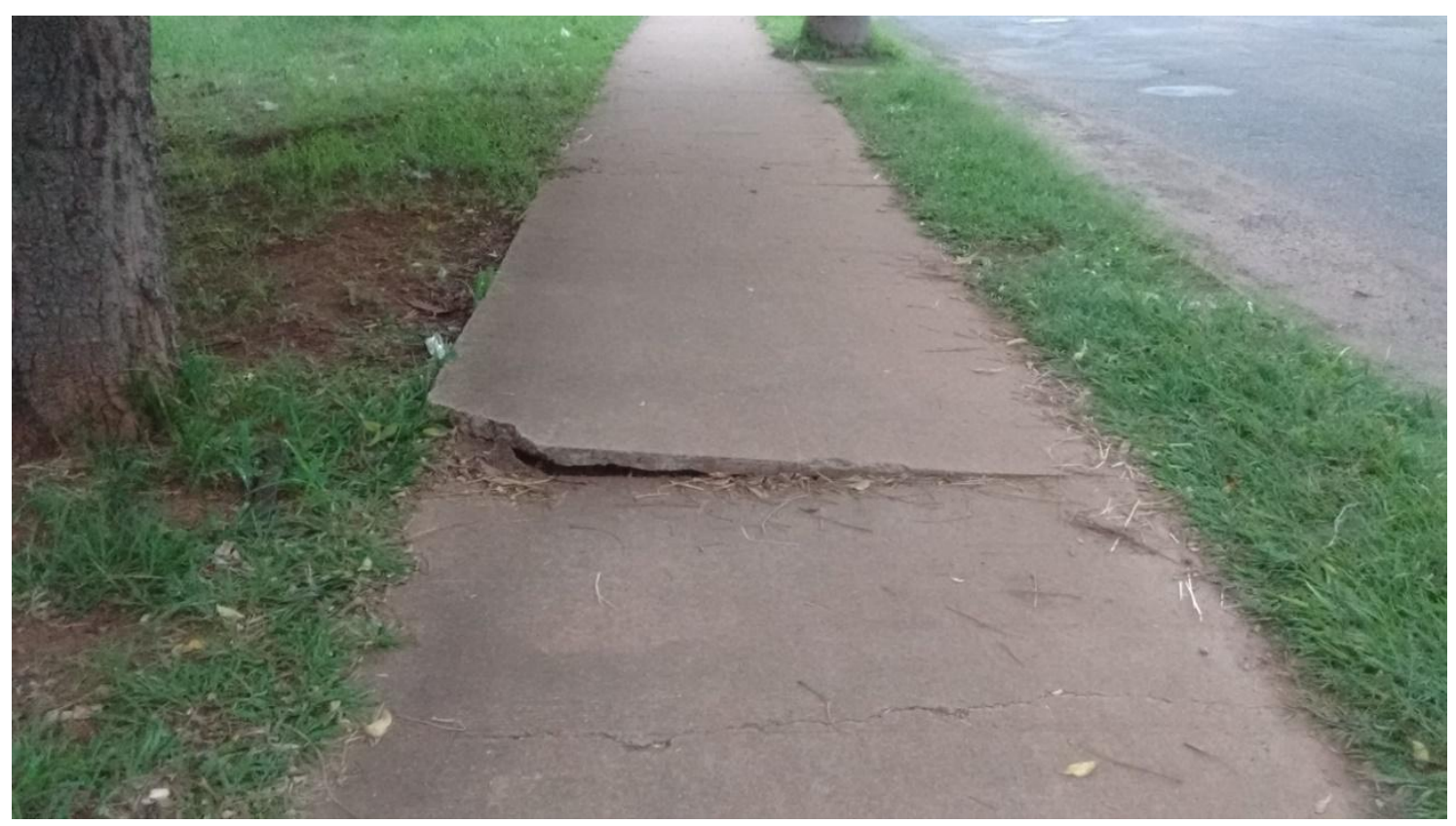

MARTINS, L.C., 2017

É recorrente o lançamento de resíduos sólidos no córrego. Atualmente, a maior parte dos resíduos sólidos depositados na área de APP são resíduos de construção civil, tais como vasos sanitários e pias, tijolos, cimento, canos, cerâmica, entre outros. Ao longo de parte da pista de caminhada existem pequenas lixeiras e caçambas, porém elas não se distribuem igualmente pela extensão do parque.

É importante considerar que os bairros Mansoure Luizote de contam com EcoPontos instalados pela prefeitura municipal. Os EcoPontos funcionam como ponto de entrega voluntária de resíduos sólidos produzido por pequenos geradores. Seu objetivo é dar a destinação correta aos estes resíduos, evitando seu descarte irregular. 


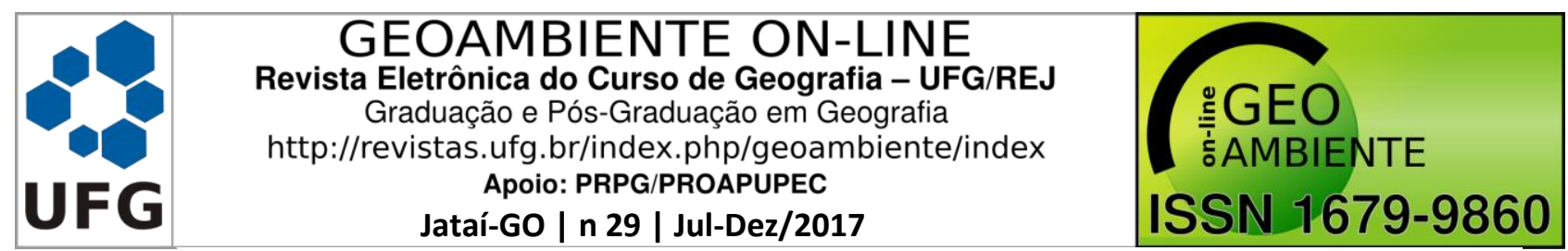

Alguns exemplos de resíduos recebidos nos EcoPontos são resíduos de construção civil como tijolos, telhas, argamassa, concreto, tubos, plásticos, papel/papelão, metais, vidros, madeiras, produtos fabricados com gesso, poda de árvores, recicláveis, sofás, armários, pias e vaso sanitário. Entre todos tipos de resíduos descartados na área de APP correspondente ao Parque Linear (Figura 3), maioria poderiam ser descartados nos EcoPontos.

Figura 3: Resíduos descartados no Parque Linear do Córrego do Óleo

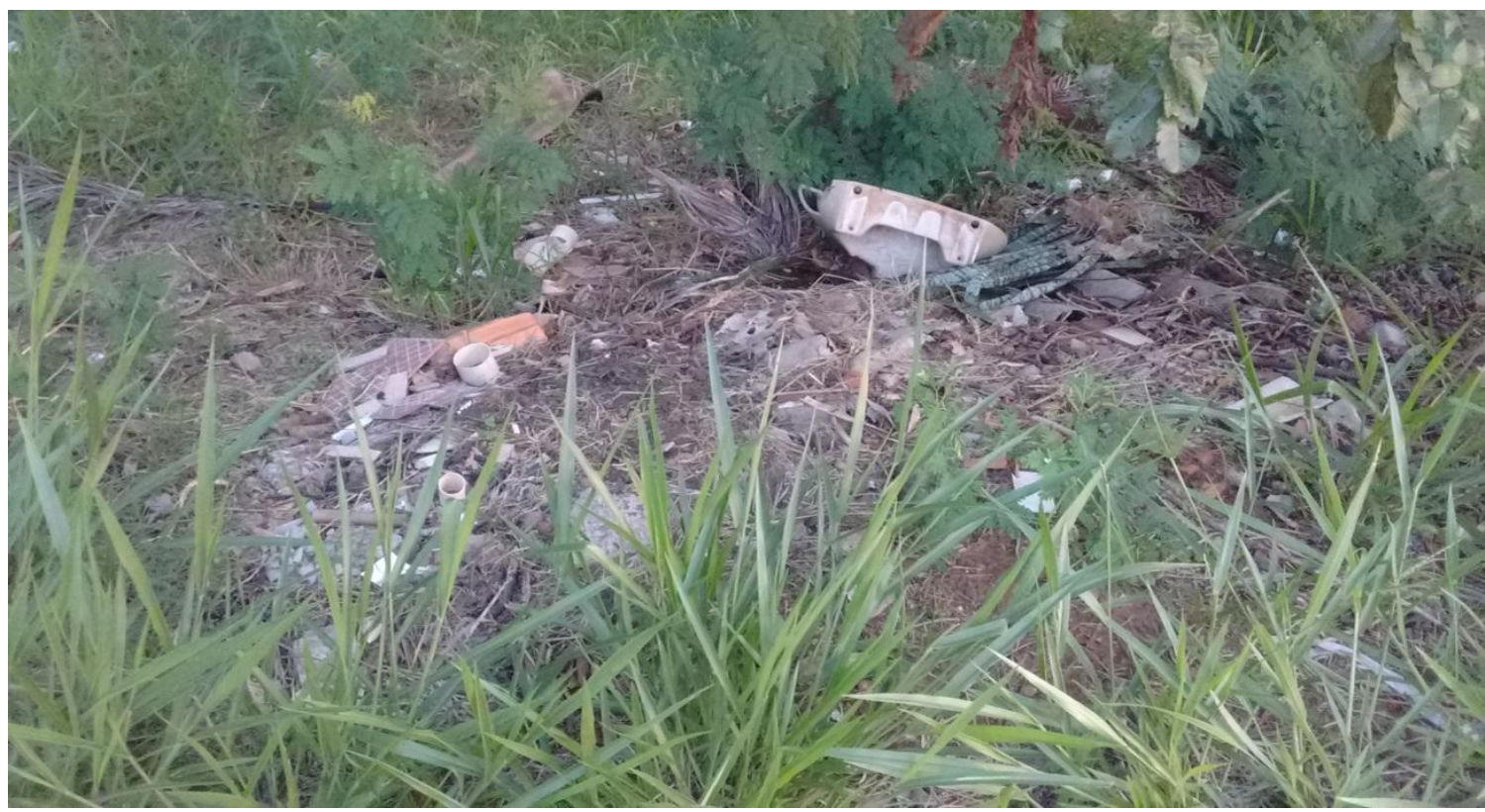

MARTINS, L.C., 2017

A ocupação da área de APP por moradias fixas ou provisórias também é um ponto importante a ser ressaltado. A área é utilizada para instalações provisórias de famílias carentes, que ocupam uma pequena porção da área por algum tempo e se deslocam para outros locais da cidade (Figura 4). Esta ocorrência ressalta o que é frequentemente destacado por diversos autores que estudam áreas de APP urbanas, além de ser um dos principais pontos discutidos na legislação urbana ao tratar dessas áreas (SEPE et al, 2014), porém ainda é um problema comum a ser estudado com mais afinco.

Os equipamentos urbanos inaugurados pela prefeitura em 2014 (Figura 5) são uma das maiores atratividades do parque. A quadra de esportes e os bancos são amplamente frequentados pela população. Esta área, entretanto, necessita de algumas intervenções em sua estrutura, principalmente no solo. Alguns caminhos alternativos não pavimentados são 


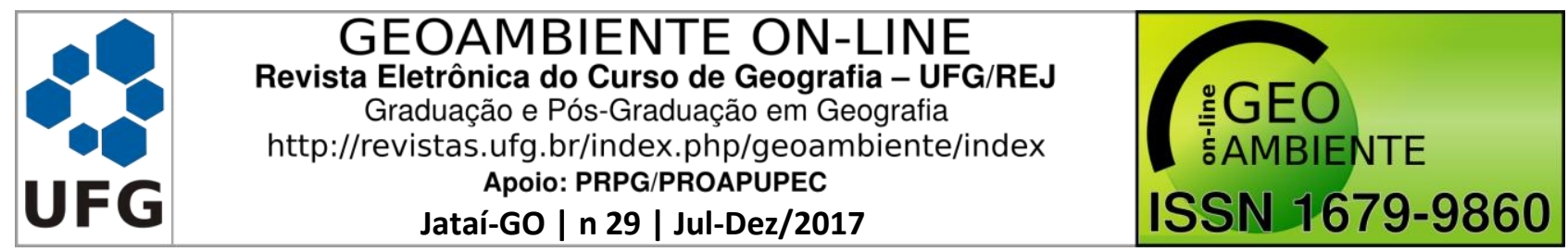

utilizados pela população, até mesmo como ciclovia, e algumas intervenções iniciadas permanecem inacabadas, o que potencializa a degradação deste espaço.

Entre as intervenções que estimulam a interação entre a população e o Parque Linear, é possível destacar ações pontuais como a fazendinhacriada na área de APP por iniciativa de um aposentado. O espaço é dotado de uma estrutura que estimula a interação de crianças com a área com espaços como uma horta, balanços, labirinto, casa na árvore, espaço para leitura, entre outros. (Figura 6),

Figura 4: Moradias improvisadas no Parque Linear do Córrego do Óleo

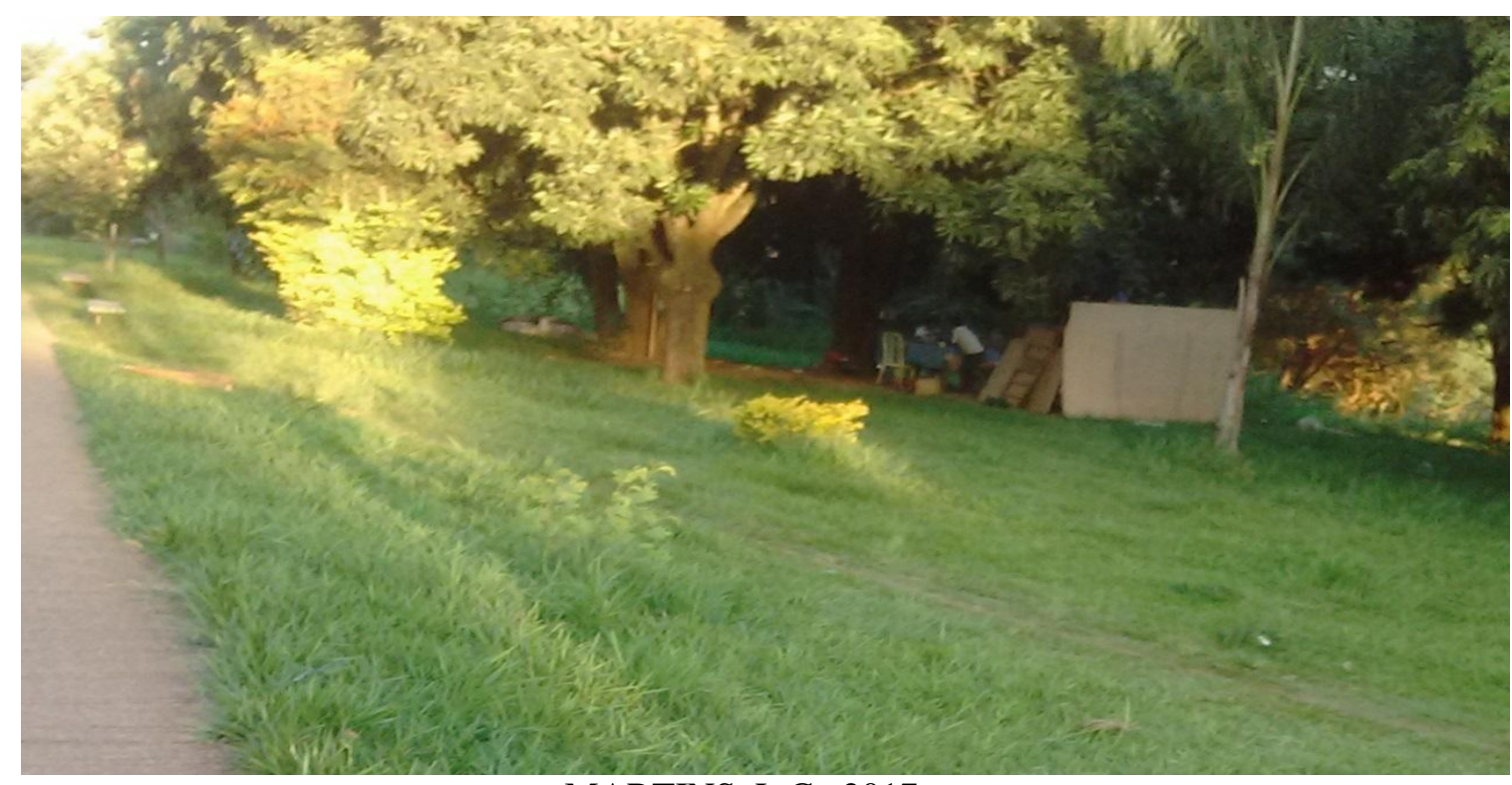

MARTINS, L.C., 2017

Figura 5: Área de Lazer no Parque Linear do Córrego do Óleo 


\begin{tabular}{|c|c|c|}
\hline UF & $\begin{array}{c}\text { GEOAMBIENTE ON-LINE } \\
\text { Revista Eletrônica do Curso de Geografia - UFG/REJ } \\
\text { Graduacãao e Pós-Graduacão em Geografia } \\
\text { http://revistas.ufg.br/index.php/geoambiente/index } \\
\text { Apoio: PRPG/PROAPUPEC } \\
\text { Jatai-GO | n 29 | Jul-Dez/2017 }\end{array}$ & $\begin{array}{l}\text { :GEO } \\
\text { ISAMBIENTE } \\
\text { ISSN } 1679-9860\end{array}$ \\
\hline
\end{tabular}

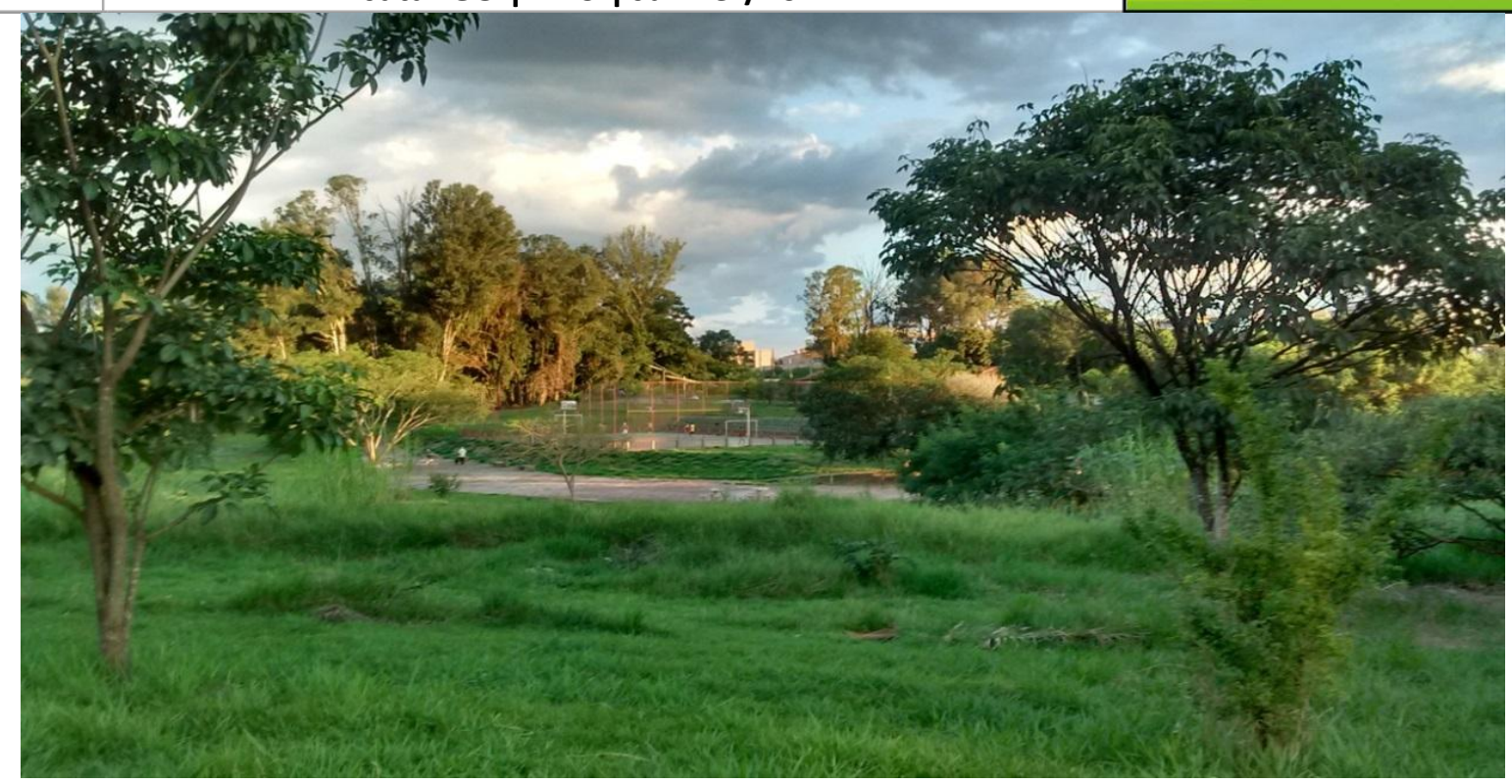

MARTINS, L.C., 2017

Figura 6: Fazendinha do Parque Linear do Córrego do Óleo

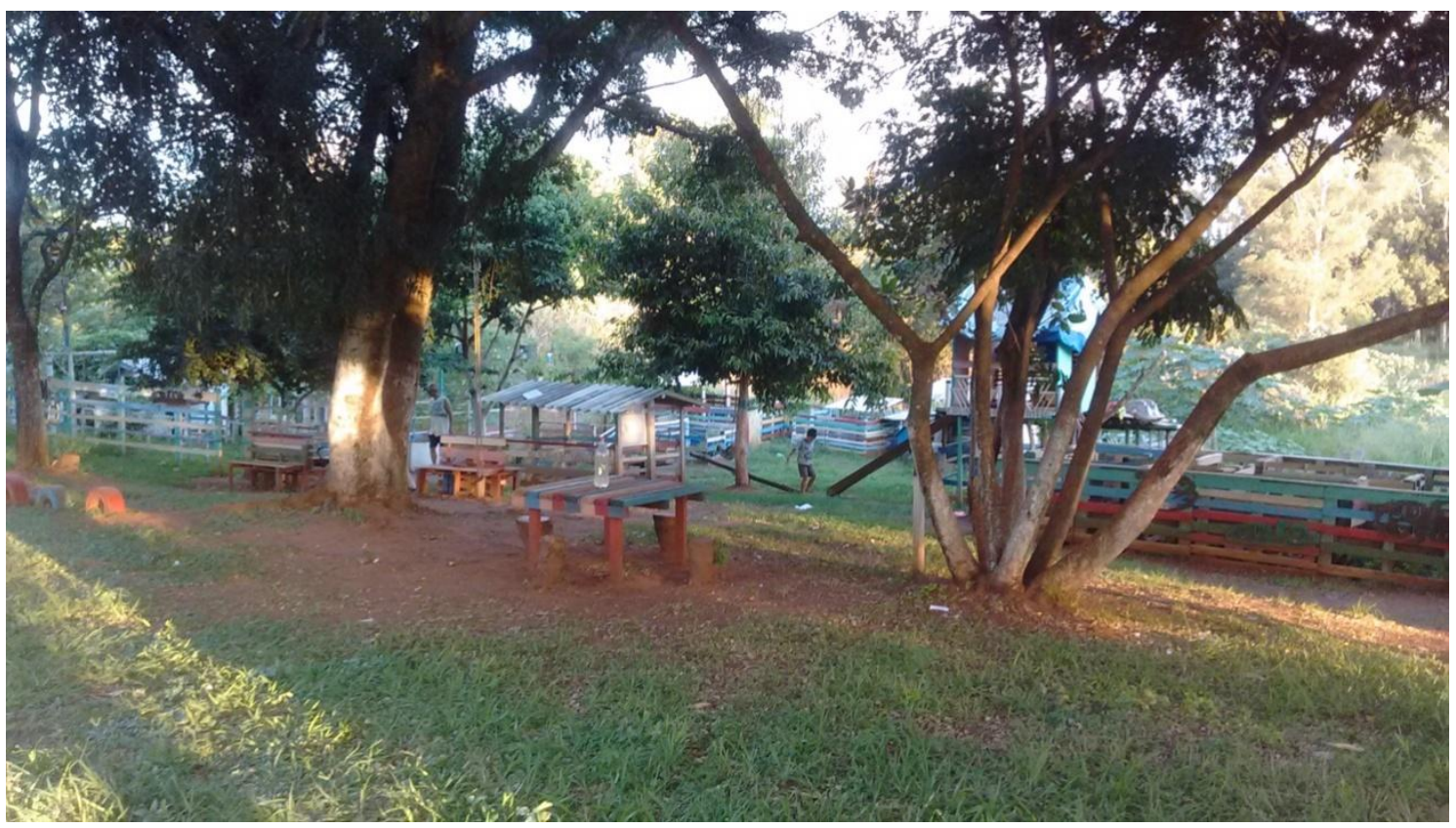

MARTINS, L.C., 2017

É necessário um cuidado especial com tais iniciativas, pois algumas vezes elas demandam de um acompanhamento profissional, sobretudo no que diz respeito à própria infraestrutura, para que seja garantido o equilíbrio entre a utilização do espaço da APP que é 


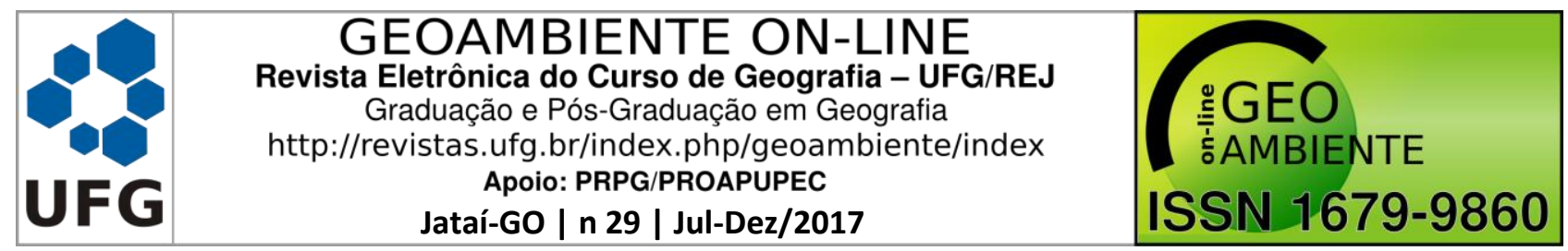

especialmente destinado a estes tipos de uso por parte da população, e a preservação das margens do córrego.

É possível inspirar intervenções futuras neste espaço, pois é notável a contribuição dele para a interação entre a população e o parque e a possibilidade de realizar iniciativas contínuas e eficazes de educação ambiental, motivadas a priori pela própria convivência das crianças e pais com a área.

\section{Percepção da população local}

Entre os 30 entrevistados nesta pesquisa, 53,3\% residem no bairro Mansour, 20\% no Luizote de Freitas, 6,7\% Cidade Verde e $20 \%$ em outros bairros. Com relação à frequência no Parque Linear, a maior parte dos entrevistados não frequenta (34\%) ou frequenta apenas uma vez por semana $(34 \%)$.

Se não soubessem que a área em questão é um Parque Linear, $25 \%$ dos entrevistados a classificariam apenas como um córrego e 12\% como uma pista de caminhada ou calçada. Cabe ressaltar algumas definições citadas pontualmente pelos entrevistados como brejo e mata. Tais respostas indicam que não há uma clareza da população quanto ao conceito de um Parque Linear.

Entre os principais motivos que fazem a população querer frequentar o Parque Linear estão a pista de caminhada e a possibilidade de praticar exercícios $(30 \%)$ e o ar fresco e tranquilidade (25\%).Em contrapartida, a criminalidade e falta de segurança (33\%) e o lixo acumulado (15\%) foram os principais motivos pelos quais os entrevistados não frequentam o Parque Linear.

É importante saber o que motiva a população a frequentar o local, não apenas para compreender a relação da população com o córrego e com áreas preservadas em geral, mas principalmente para que haja resultados satisfatórios em investimentos no Parque Linear e para elaborar ações de educação ambiental mais efetivas.

Da mesma maneira, os motivos destacados pela população para não frequentar o Parque Linear orientam ações até mesmo para que sua construção não tenha sido um 


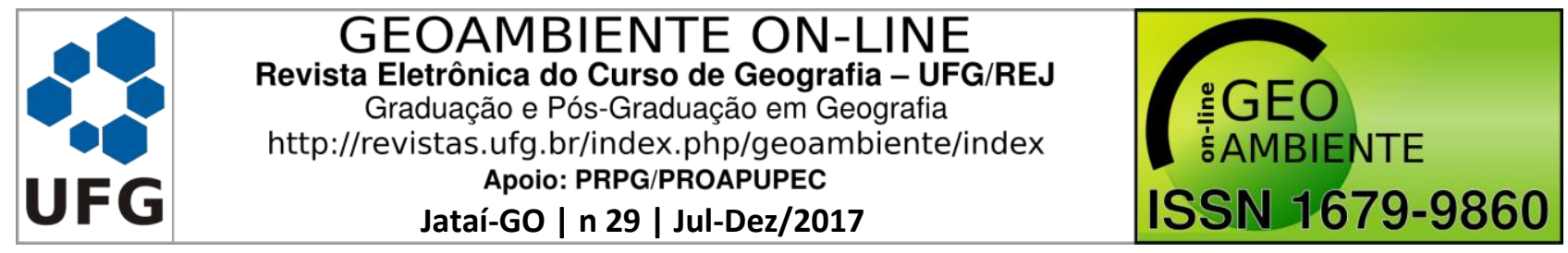

investimento oneroso e que não apresenta a utilidade buscada pelo objetivo inicial da construção deste espaço.

Segundo os entrevistados, o Parque Linear é importante para a preservação da mata e do córrego (38\%) e para a prática de exercícios físicos e lazer (30\%).

Os principais problemas observados no Parque Linear foram a criminalidade e falta de segurança $(43 \%)$ e a falta de iluminação (28\%). Entre outros problemas destacados estão a falta de cuidado com a vegetação, poucas opções de lazer, a quantidade de lixo acumulado e a falta de cuidado com a vegetação.

Algumas melhorias sugeridas pelos entrevistados para o Parque Linear, estão: mais iluminação (43\%), mais segurança (20\%) e menos lixo e mais caçambas e lixeiras(16\%). Outras melhorias foram sugeridas na estrutura de esportes e na pista de caminhada e no cuidado com as árvores e a vegetação de maneira geral.

Caso as melhorias sugeridas fossem implementadas, $82 \%$ dos entrevistados afirmaram que frequentariam mais o Parque Linear. Além disso, 100\% dos entrevistados são a favor da criação de Parques Lineares com tais estruturas em outros locais da cidade.

Apesar da compreensão superficial do conceito de Parque Linear, a população entende a necessidade de preservação do Parque Linear. Boa parte dos entrevistados não sabia da existência dos EcoPontos dos bairros Luizote de Freitas e Mansour, o que mostra que a implantação destes pontos não é suficiente.

A construção de espaços como o Parque Linear e a conservação das APPs urbanas são de extrema importância para a manutenção do equilíbrio ambiental nas cidades e para a aproximação entre os cursos d'água, parte presente da natureza no tecido urbano, e a população. Entretanto, a simples construção destes espaços não garante este resultado.

Portanto, o cuidado com a vegetação preservada, a manutenção das estruturas criadas nestes espaços, não somente estruturas de lazer, mas a estrutura básica como bancos, iluminação, lixeiras, bebedouros, entre outros, a partir de um monitoramento contínuo, e a discussão com a população antes, durante e após a sua criação são medidas necessárias para que o Parque Linear exerça sua função ambiental e social na cidade. 


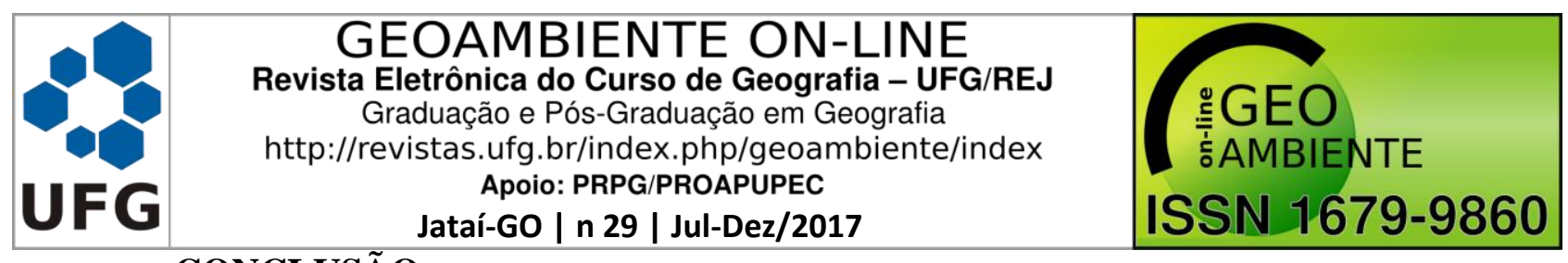

CONCLUSÃO

- O Parque Linear é um espaço importante para a conservação ambiental do Córrego do Óleo, para o convívio da população dos bairros próximos com sua área de preservação permanente e para a prática de atividades físicas, interação social, entre outros benefícios, como foi mencionado pelos entrevistados.

- Entretanto, esta pesquisa indicou a necessidade de algumas intervenções a nível estrutural, como melhorias na pista de caminhada, nos equipamentos de lazer, na iluminação, e ambiental, como a retirada do entulho existente no Parque Linear do Córrego do Óleo, o cuidado com a vegetação arbustiva e o plantio de árvores, e social, como garantia de maior segurança e maior variedade de atividades de lazer.

- Algumas estruturas tiveram sua construção iniciada, mas encontram-se atualmente incompletas, como a ciclovia, a instalação de lixeiras e postes de iluminação. Estes fatores, assim como os problemas encontrados, afastam a população do Parque Linear e desta maneira, inibem um empenho maior para sua conservação.

- A avaliação das condições ambientais e estruturais e as respostas da população dos bairros vizinhos ao Parque Linear ao questionário aplicado oferecem subsídios importantes para ações de educação ambiental, como a informação da população a respeito dos Ecopontos dos bairros Luizote de Freitas e Mansour, e para a elaboração de futuros projetos como atividades de lazer e cultura, prevenção à criminalidade, plantio de árvores, entre outros.

\section{REFERÊNCIAS BIBLIOGRÁFICAS}

BAPTISTA, M.; CARDOSO, A. Rios e cidades: Uma longa e sinuosa história. Belo Horizonte, Revista UFMG, v. 20, n.2, p. 124-153, jul.-dez. 2013.

BEZERRA, M.C.L.; ROCHA, M.A.; BOGNIOTTI, G.M.C. Qualidade dos espaços verdes urbanos: o papel dos parques de lazer e de preservação. USJT, ARQ.URB, São Paulo, n. 15, p. 128-142, jan-abr 2016.

CABRAL, A.S.C. Os córregos ocultos na paisagem urbana:o caso da bacia do Carajás.

Revista Anagrama, São Paulo, v 5, n 3, p. 1 - 34, Mar-Mai, 2012. 


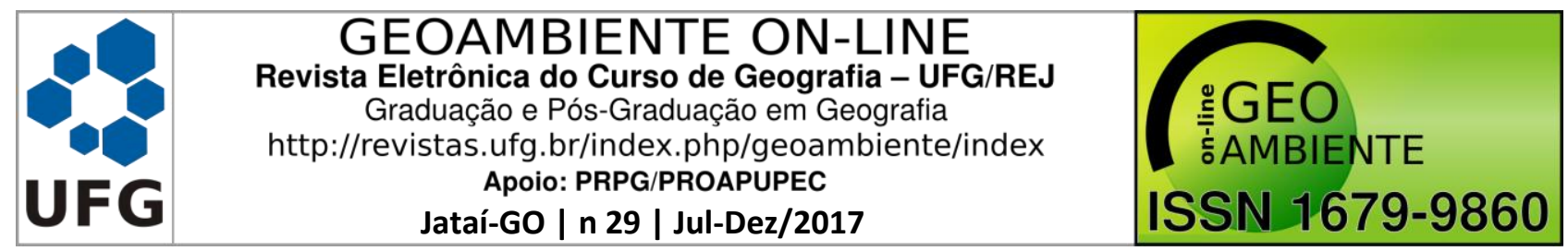

COTA, G.E.M.; COMINI, L.M.B.; PEDRAS, K.C.; LIMOEIRO, B.F.; PARREIRAS, G.O.

Os parques lineares como alternativa às canalizações - reflexões a partir do Projeto Drenurbs, Belo Horizonte (MG). In: Encontro Nacional de Geógrafos, 18, São Luís. $\quad$ Anais... São Luís.

<http://www.eng2016.agb.org.br/resources/anais/7/1468265280_ARQUIVO_Artigo-

ENG.pdf> Acesso em 01 abr 2017.

FARIAS, E.M.C.; NASCIMENTO, L.A.; SANTOS, M.S.M.; SOUZA, M.M.O.; SOARES, A.M. O Córrego do Óleo em Uberlândia-MG: Caracterização e condições de conservação ambiental. Revista da Católica, Uberlândia, v. 1, n. 2, p. 105-118, 2009.

FRIEDRICH, D. O Parque linear como instrumento de planejamento e gestão das áreas de fundo de vale urbanas. Dissertação (Mestrado). Faculdade de Arquitetura, Universidade Federal do Rio Grande do Sul. Porto Alegre, 2007.

GALENDER, F.C. A ideia de sistema de espaços livres públicos na ação de paisagistas pioneiros da América Latina. Paisagens em Debate. São Paulo: FAU/USP,n.3, p.1-8,nov, 2005.

GRISE, M.M.; BIONDI, D.; ARAKI, H. A floresta urbana da cidade de Curitiba, PR. Floresta, Curitiba, PR, v. 46, n. 4, p. 425 - 438, out.-dez. 2016.

LARA, M.V.R. Análise crítica de programas de revitalização de rios urbanos na bacia hidrográfica do Rio Belém em Curitiba-PR.Dissertação (Mestrado). Programa de PósGraduação em Meio Ambiente Urbano e Industrial, Universidade Federal do Paraná. Curitiba, 2014.

MACEDO, D.R. Avaliação de Projeto de Restauração de Curso d'água em Área Urbanizada: estudo de caso no Programa Drenurbs em Belo Horizonte. Dissertação (Mestrado).Instituto de Geociências, Departamento de Geografia, Universidade Federal de Minas Gerais. Belo Horizonte, 2009.

MACIEL, T.T.; BARBOSA. B.C. Áreas verdes urbanas:História, conceitos e importância ecológica .Revista CES, Juiz de Fora, v. 29, n. 1. p. 30-42, jan./jul. 2015. 


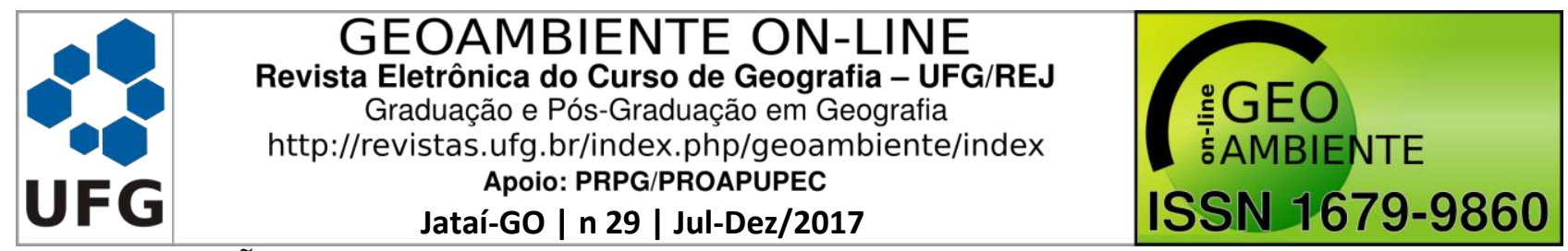

MAGALHÃES, C.S.; SILVA, T.S. Caracterização do estado de conservação ambiental do parque natural municipal do óleo, Uberlândia - MG. In: Semana Nacional de Ciência e Meio Ambiente, 2. Anápolis. Anais... : Curitiba, UNIEvangélica. 2011.

PEREIRA, D.C.; RIBEIRO, F.A.B.S. Programa de recuperação de áreas degradadas nas margens do Córrego do Óleo. In: Congresso Brasileiro de Gestão Ambiental. 3. Goiânia. Anais... Goiânia, Instituto Brasileiro de Estudos Ambientais. 2012.

Prefeitura Municipal de Uberlândia - PMU. Parque Natural Municipal das Graças: Estudos para criação. Secretaria Municipal de Meio Ambiente,Uberlândia-MG, 2015, 78 p. Disponível em: 〈http://www.uberlandia.mg.gov.br/uploads/cms_b_arquivos/13427.pdf> Acesso em 02 abr 2017.

ROLNIK, R. Para morar e para criar. Entrevista à Efêmero concreto. Mar. de 2012. Disponível em http:<//efemeroconcreto.com.br/?p=40>. Acesso em 31 mar. 2012.

SEPE, P.M.; PEREIRA, H.M.S.B.; BELLENZAN, M.L. O novo Código Florestal e sua aplicação em áreas urbanas: uma tentativa de superação de conflitos? In: Seminário Nacional sobre o Tratamento de Áreas de Preservação Permanente em Meio Urbano e Restrições Ambientais ao Parcelamento do Solo, 3, 2014. Anais... Belém, ANPUR, 2014.

TUCCI, C. E. M. .Inundações Urbanas. 1. ed. Porto Alegre: ABRH, 2007. v. 1. 352 p.

UBERLÂNDIA. Lei Complementar n. 525, 14 de abril de 2011. Dispõe sobre o zoneamento do uso e ocupação do solo do município de Uberlândia e revoga a Lei Complementar n. 245, de 30 de novembro de 2000 e suas alterações posteriores. Diário Oficial do Município n. 3643, de 14 de abr. 2011. 